\title{
Qualidade do suco de maracujá-amarelo em diferentes épocas de colheita
}

\author{
Quality of the juice of yellow passion fruit in different harvest seasons
}

\author{
Thais VIANNA-SILVA ${ }^{1}$, Eder Dutra de RESENDE ${ }^{2 *}$, Alexandre Pio VIANA³, Silvia Menezes de Faria PEREIRA ${ }^{4}$, \\ Lanamar de Almeida CARLOS ${ }^{4}$ Letícia VITORAZI ${ }^{5}$
}

\section{Resumo}

A produção de maracujá-amarelo é sazonal e ocorre nas safras de inverno e de verão. O objetivo do trabalho foi avaliar a influência de duas diferentes épocas de colheita sobre a qualidade do suco dos frutos de maracujá-amarelo, em sete estádios de maturação. Os experimentos foram constituídos de 2 épocas de colheita (EP 1 e EP 2) e 7 estádios de maturação, com 10 repetições. Os resultados foram avaliados pelo teste de Tukey a $5 \%$ de probabilidade. Na EP 1, marcada por temperaturas mais amenas e menor precipitação total, os frutos apresentaram maior acidez titulável (AT), maior conteúdo de Sólidos Solúveis Totais (SST), maior conteúdo de MS e razão SST/AT, e menor pH até o estádio de amadurecimento com $65 \%$ de cor amarela, quando comparados com a EP 2. A partir deste estádio não foi encontrada diferença significativa no conteúdo de SST entre as épocas de colheita, porém o suco dos frutos totalmente maduros apresentou menores conteúdos de matéria seca e da razão SST/AT na EP 1, além de uma acidez mais elevada. Concluiu-se que os maracujás-amarelos podem ser colhidos com $65 \%$ de cor amarela da casca na época EP 1, pois não apresentam alterações químicas posteriores, mas na época EP 2 os frutos apresentaram um incremento da razão SST/AT até o estádio maduro.

Palavras-chave: maracujá-amarelo; Passiflora edulis f. flavicarpa D.; suco; amadurecimento.

\begin{abstract}
Yellow passion fruit presents seasonal production and occurs in the winter and summer harvest seasons. The aim of this work was to evaluate the influence of two different harvest seasons on the quality of yellow passion fruit (Passiflora edulis $\mathrm{f}$. flavicarpa Degener) juice, in seven maturation stages. The experiments were constituted of two harvest seasons (EP 1 and EP 2) and seven maturation stages, with 10 repetitions. The results were evaluated through the Tukey test at a 5\% probability level. In EP 1, characterized by lower temperatures and lower total precipitation, the fruits presented higher Total Titratable Acidity (TTA), total soluble solids content (TSS), dry matter and TSS/TTA ratio, and lower $\mathrm{pH}$, until the ripening stage of $65 \%$ yellow color of the peel, when compared with EP 2. After this stage no difference in TSS content between harvest seasons was found. However, the juice of totally mature fruits presented lower contents of dry matter and TSS/TTA ratio in the EP 1 season, as well as higher acidity. It was concluded that yellow passion fruit can be harvested with $65 \%$ yellow color of the peel in harvest season EP 1, due to the maintenance of chemical quality; however, in harvest season EP 2, the fruits showed an increase in the TSS/TTA ratio until the mature stage.

Keywords: yellow passion fruit; Passiflora edulis f. flavicarpa D.; juice; ripening.
\end{abstract}

\section{Introdução}

A produção mundial de maracujá se concentra na América do Sul. O Brasil, a Colômbia, o Peru e o Equador são responsáveis por cerca de $90 \%$ da exportação de suco concentrado congelado e polpa de maracujá (SOUZA et al., 2002; ARAÚJO et al., 2000; RUGGIERO et al., 1996).

O Brasil é o principal país produtor e consumidor de maracujá-amarelo. A produção brasileira de maracujá, no ano de 2004, foi de 491.619 toneladas em uma área plantada de 37.252 ha. (IBRAF, 2007). Esta produção engloba todos os estados brasileiros e o Distrito Federal, apresentando boas perspectivas para ampliação da área cultivada. A Bahia se destaca como o maior produtor, com 125.741 toneladas, o Espírito Santo com 63.021, São Paulo com 56.957, o Rio de Janeiro com 41.500 e o Sergipe com 37.830 (HAFLE, 2005).

O maracujá azedo (Passiflora edulis f. flavicarpa) representa aproximadamente $97 \%$ da área plantada e do volume comercializado. Estima-se que mais de $60 \%$ da produção brasileira de maracujá azedo seja destinada ao consumo in natura, através de sacolões, feiras, supermercados. O restante da produção

Recebido para publicação em 12/2/2007

Aceito para publicação em 19/10/2007 (002298)

${ }^{1}$ Centro de Ciências e Tecnologias Agropecuárias - CCTA, Universidade Estadual do Norte Fluminense - UENF, E-mail: tavianna@gmail.com

${ }^{2}$ Centro de Ciências e Tecnologias Agropecuárias - CCTA, Laboratório de Tecnologia de Alimentos - LTA, Universidade Estadual do Norte Fluminense - UENF,

Av. Alberto Lamego, 2000, Parque Califórnia, CEP 28013-602, Campos dos Goytacazes - RJ, Brasil, E-mail: eresende@uenf.br

${ }^{3}$ Centro de Ciências e Tecnologias Agropecuárias - CCTA, Laboratório de Melhoramento Genético Vegetal - LMGV, Universidade Estadual do Norte Fluminense - UENF,

E-mail: pirapora@uenf.br

${ }^{4}$ Centro de Ciências e Tecnologias Agropecuárias - CCTA, Laboratório de Tecnologia de Alimentos - LTA, Universidade Estadual do Norte Fluminense - UENF,

E-mail: silvia@uenf.br, lanamar@uenf.br

${ }^{5}$ Conselho Nacional de Desenvolvimento Científico e Tecnológico - Cnpq, Universidade Estadual do Norte Fluminense - UENF, E-mail: vitorazi@uenf.br

${ }^{*}$ A quem a correspondência deve ser enviada 
é destinada às indústrias de processamento, sendo o suco o principal produto (ROSSI et al., 2001).

A colheita do maracujá-amarelo é feita quando os frutos estão caídos no chão ou presos nas ramagens da planta, num estádio de maturação em que a casca encontra-se com coloração amarela bem mais acentuada do que a verde. Nessas condições, as perdas devido à desidratação e à contaminação por microrganismos, com conseqüente apodrecimento, aumentam a perecibilidade e reduzem o período de conservação pós-colheita do fruto (SALOMÃO, 2002; MARCHI et al., 2000; BERTHIER et al., 2000; DURIGAN, 1998).

Durante o amadurecimento, os frutos do maracujazeiro sofrem diversas mudanças em sua composição físico-química, que está intrinsecamente relacionada com o ponto de colheita (GAMARRA; ROJAS; MEDINA, 1994). Diversos fatores influenciam a composição dos frutos, como: estádio de maturação, época de colheita, condições de armazenamento, variabilidade genética, práticas culturais e adubação.

Silva et al. (2005), estudando a influência dos estádios de maturação sobre as características químicas do suco de maracujá-amarelo, identificaram que os frutos poderiam ser consumidos com $65 \%$ de cor amarela da casca, pois a partir desta fase o suco apresentou ótimos teores de Sólidos Solúveis Totais (SST), Acidez Titulável (AT) e razão SST/AT.

Ritzinger et al. (1989), avaliando a qualidade do maracujáamarelo em diferentes épocas de colheita no município de Viamão, Rio Grande do Sul, verificaram que a composição dos frutos pode ser influenciada por fatores climáticos. Em épocas com menor precipitação e temperatura ocorreu diminuição no teor de açúcares redutores e na razão SST/AT do suco quando comparadas com épocas de mais altas temperaturas. Entretanto, no trabalho utilizaram somente três estádios de maturação do maracujá, determinados subjetivamente para caracterizar os frutos verdes, parcialmente maduros e totalmente maduros.

O presente trabalho avalia a influência de duas épocas de colheita sobre as características químicas do suco de maracujáamarelo, contemplando todo o período de amadurecimento dos frutos em sete estádios de maturação.

\section{Material e métodos}

No trabalho foram utilizados frutos de maracujazeiroamarelo (Passiflora edulis $f$. flavicarpa Degener), colhidos em lavoura localizada no município de Campos dos Goytacazes, RJ. O solo é do tipo Argissol Amarelo, desenvolvido a partir de sedimentos terciários, horizonte B textural com camada superficial arenosa e relevo suavemente ondulado, que caracterizam bem as condições edafoclimáticas do local onde, geralmente, se cultiva esta fruteira, na região Norte Fluminense (CARVALHO et al., 2000).

Os experimentos foram conduzidos em Delineamento Inteiramente Casualizado no esquema fatorial $2 \times 7$, constituído de 2 épocas de colheita e 7 estádios de maturação, com 10 repetições. Os resultados foram processados através do programa GENES de análises estatísticas (CRUZ, 2001), utili- zando para comparação das médias o teste de Tukey a 5\% de probabilidade.

A época de colheita 1 (EP 1) compreendeu o período de maio a setembro de 2003, em que as condições climáticas foram caracterizadas por temperaturas mais amenas e de menor precipitação total. A época de colheita 2 (EP 2) foi conduzida entre os meses de outubro a dezembro de 2003, sendo caracterizada por temperaturas médias mais altas e de maior precipitação.

$\mathrm{Na}$ colheita, frutos de aproximadamente $210 \mathrm{~g}$ foram selecionados seguindo critérios de homogeneização quanto ao estádio de maturação, uniformidade em tamanho e boas condições fitossanitárias. Iniciando-se quando os frutos apresentavam os primeiros sinais de mudança de cor da casca até quando atingiram o total amarelecimento.

Os frutos foram colhidos pela manhã e transportados para o laboratório onde foram lavados e secos para a condução das análises.

A coloração dos frutos foi medida com auxílio do colorímetro HUNTERLAB MINISCAN SPECTROPHOTOMETER em quatro pontos eqüidistantes da região mediana da parte superior dos frutos e caracterizada pelo parâmetro de Hunter $b$, que permite avaliar a evolução da cor amarela da casca do maracujá. Foi definida uma escala de cor compreendendo cada um dos sete estádios de maturação, obtida pela diferença entre o índice de cor de cada estádio de maturação e aquele do estádio verde, e dividindo pela variação total do índice de cor amarela durante o período de amadurecimento (SILVA, 2004).

Para as análises químicas do suco, os frutos foram partidos na região equatorial, para retirada da polpa bruta. $\mathrm{O}$ material foi batido em um misturador Arno sem danificar as sementes e filtrado em espremedor manual com tela filó para a extração do suco.

A cor do suco foi medida pelo colorímetro de Hunter, utilizando-se $20 \mathrm{~mL}$ de suco em uma cubeta de amostra cilíndrica medindo 5,0 cm de diâmetro e 2,5 cm de altura, adaptada em copo escuro opaco para evitar interferência de luz externa. A referência de cor foi medida com placas de calibração com padrões de reflectância $L, a, b$.

$\mathrm{Na}$ caracterização química do suco avaliou-se o conteúdo de Matéria Seca (MS), medido em estufa a $105^{\circ} \mathrm{C}$ por 48 horas (AOAC, 1970); o teor de Sólidos Solúveis Totais (SST) determinado por meio de refratômetro digital ATAGO Modelo PR-201, expresso em ${ }^{\circ}$ Brix; a Acidez Titulável (AT) determinada por titulação potenciométrica com $\mathrm{NaOH} 0,1 \mathrm{~N}$ e expressa em $\%$ de ácido cítrico; o pH foi medido com pHmetro WTW Modelo 330. Finalmente, determinou-se a razão SST/AT do suco.

\section{Resultados e discussão}

\subsection{Coloração da casca}

A evolução da cor amarela, caracterizada pelo parâmetro de Hunter $b$, em sucessivos estádios de maturação ao longo de duas épocas de colheita está indicada na Tabela 1. A análise de variância dos resultados mostrou que os frutos colhidos na EP 1 
apresentaram os mesmos índices de cor com relação àqueles colhidos na EP 2, dentro de um mesmo estádio de maturação, possibilitando, portanto, a definição de uma escala de cor comum para os frutos nas distintas épocas de colheita.

A utilização da escala de cor permite a homogeneização dos estádios de maturação nas diferentes safras estudadas, uma vez que o índice de maturação baseado no período após a antese dos maracujás é alterado pelas condições climáticas. Na época EP 2 os frutos totalmente amarelos foram colhidos com 83 dias após a antese e na EP 1 este período se estendeu até 100 dias após a antese. Avaliações subjetivas indicaram a presença de frutos verdes e maduros dentro de um mesmo tempo após a antese, apresentando, portanto, diferentes estádios de maturação que podem ser atribuídos à variabilidade genética da espécie.

O incremento da cor amarela ocorre devido à degradação da clorofila, enquanto os pigmentos amarelos, alaranjados e vermelhos pertencentes ao grupo dos carotenóides são revelados ou sintetizados. Tais pigmentos são bastante comuns e sua presença é um sinal por meio do qual o consumidor avalia a maturidade e a qualidade dos frutos (AWAD, 1993).

Dentre os fatores que influenciam a composição dos carotenóides, o estádio de maturação dos frutos é o mais importante, já que a sua biossíntese aumenta drasticamente com o amadurecimento (NASCIMENTO, 1996).

\subsection{Coloração do suco}

Os resultados das medidas de cor do suco do maracujáamarelo caracterizadas pelos parâmetros de Hunter $L, a$ e $b$ encontram-se na Tabela 2. A análise estatística dos dados mostrou que a época de colheita não influenciou os parâmetros de cor do suco.

Tabela 1. Médias do parâmetro de Hunter $b$ para a Região Superior (RS) da casca do maracujá-amarelo, na época de colheita 1 (EP 1 - maio/ setembro) e na época de colheita 2 (EP 2 - outubro/dezembro) em sete diferentes estádios de maturação.

\begin{tabular}{cccccccc}
\hline \multicolumn{7}{c}{ Estádios de maturação (\% de cor amarela) } \\
\hline $\begin{array}{c}\text { Época de } \\
\text { colheita }\end{array}$ & 0 & 4,67 & 21,26 & 28,53 & 65,95 & 82,43 & 100 \\
\hline EP 1 & $10,94^{\mathrm{Ad}}$ & $11,28^{\mathrm{Ad}}$ & $15,65^{\mathrm{Ac}}$ & $17,99^{\mathrm{Ac}}$ & $26,33^{\mathrm{Ab}}$ & $29,18^{\mathrm{Ab}}$ & $36,03^{\mathrm{Aa}}$ \\
EP 2 & $9,44^{\mathrm{Ae}}$ & $11,39^{\mathrm{Ae}}$ & $14,55^{\mathrm{Ad}}$ & $15,78^{\mathrm{Ad}}$ & $25,68^{\mathrm{Ac}}$ & $32,28^{\mathrm{Ab}}$ & $36,54^{\mathrm{Aa}}$ \\
\hline
\end{tabular}

Médias seguidas das mesmas letras maiúsculas nas colunas e minúsculas nas linhas não diferem significativamente entre si pelo teste de Tukey a $5 \%$ de probabilidade.
A luminosidade do suco (Hunter $L$ ) e a pigmentação alaranjada (Hunter $b$ ) apresentaram variações significativas em estádios intermediários de maturação (Tabela 2). A pigmentação avermelhada caracterizada pelo parâmetro de Hunter $a$ não apresentou variação significativa ao longo dos estádios de maturação. Ressalta-se, contudo, que os índices de cor do suco apresentaram magnitudes similares entre os frutos dos estádios iniciais de maturação e aqueles com 100\% de coloração amarela da casca.

Embora não tenham ocorrido diferenças significativas das medidas dos parâmetros de Hunter entre as duas épocas de colheita, nota-se que na EP 1 ocorreram tendências de menores índices de Hunter $L$ e $b$ e maiores índices de Hunter $a$ (Tabela 2). Sepúlveda et al. (1996), analisando a influência da época de colheita sobre os parâmetros da cor do suco de maracujá roxo, verificaram que os frutos colhidos no inverno apresentaram maior concentração de carotenóides em relação aos coletados no verão, intensificando a cor do suco dos frutos colhidos neste período.

Segundo Marchi et al. (2000), a evolução da cor da casca, caracterizada pelos parâmetros $\mathrm{L}^{*}, \mathrm{a}^{*} \mathrm{e} \mathrm{b}^{*}$, não está relacionada à coloração da polpa, que permaneceu praticamente constante em frutos com um terço, dois terços e inteiramente amarelados colhidos nas safras de abril, maio e junho. Notaram somente a ocorrência de índices mínimos de cor de suco em frutos com menos de dois terços de coloração amarela colhidos na safra do mês de março.

\subsection{Sólidos solúveis totais (SST)}

Na EP 1, quando a temperatura média foi mais baixa e os frutos tiveram um período mais longo após a antese, o suco apresentou concentrações médias de SST 39\% superiores às concentrações do suco dos frutos colhidos na EP 2, nos estádios de maturação com menos de $65 \%$ de cor amarela da casca (Tabela 3). Posteriormente não ocorreram diferenças entre os conteúdos de SST dos frutos colhidos em diferentes épocas. Resultados semelhantes foram encontrados por Veras et al. (2000) e Ritzinger et al. (1989), notando que os frutos com a coloração amarela mais intensa do que verde não apresentaram diferenças significativas no teor de SST em função das épocas de colheita.

Nas duas épocas de colheita notou-se um aumento significativo no conteúdo de SST do suco dos frutos colhidos entre os estádios de maturação com 28,53 e $65,95 \%$ de cor amarela.

Tabela 2. Médias do parâmetro de Hunter $L$, $a$ e $b$ do suco do maracujá-amarelo, em duas épocas de colheita (EP 1 - maio/setembro e EP 2 - outubro/ dezembro) nos sete diferentes estádios de maturação.

\begin{tabular}{|c|c|c|c|c|c|c|c|c|}
\hline \multicolumn{9}{|c|}{ Estádios de maturação (\% de cor amarela) } \\
\hline Época de colheita & Parâmetro de Hunter & 0 & 4,67 & 21,26 & 28,53 & 65,95 & 82,43 & 100 \\
\hline EP 1 & $\mathrm{~L}$ & $14,51^{\mathrm{Aa}}$ & $14,14^{\mathrm{Aa}}$ & $13,50^{\mathrm{Aab}}$ & $13,58^{\text {Aab }}$ & $14,23^{\mathrm{Aa}}$ & $12,39^{\mathrm{Ab}}$ & $14,48^{\mathrm{Aa}}$ \\
\hline EP 2 & & $16,07^{\mathrm{Aa}}$ & $16,28^{\mathrm{Aa}}$ & $15,90^{\mathrm{Aa}}$ & $15,61^{\mathrm{Aab}}$ & $13,46^{\mathrm{Ab}}$ & $14,30^{\mathrm{Aab}}$ & $14,56^{\mathrm{Aab}}$ \\
\hline EP 1 & $\mathrm{a}$ & $7,94^{\mathrm{Aa}}$ & $8,14^{\mathrm{Aa}}$ & $7,77^{\mathrm{Aa}}$ & $7,77^{\mathrm{Aa}}$ & $7,52^{\mathrm{Aa}}$ & $7,34^{\mathrm{Aa}}$ & $7,33^{\text {Aa }}$ \\
\hline EP 2 & & $4,38^{\text {Аa }}$ & $4,61^{\mathrm{Aa}}$ & $6,35^{\mathrm{Aa}}$ & $4,37^{\text {Аa }}$ & $5,34^{\mathrm{Aa}}$ & $5,51^{\mathrm{Aa}}$ & $5,15^{\mathrm{Aa}}$ \\
\hline EP 1 & $\mathrm{~b}$ & $9,28^{\mathrm{Aa}}$ & $9,01^{\mathrm{Aab}}$ & $8,73^{\mathrm{Aabc}}$ & $8,26^{\mathrm{Abc}}$ & $9,16^{\mathrm{Aa}}$ & $7,99^{\mathrm{Ac}}$ & $9,43^{\mathrm{Aa}}$ \\
\hline EP 2 & & $9,41^{\mathrm{Aab}}$ & $9,40^{\mathrm{Aabc}}$ & $9,88^{\mathrm{Aa}}$ & $8,55^{\mathrm{Ac}}$ & $8,64^{\mathrm{Abc}}$ & $8,70^{\mathrm{Abc}}$ & $8,97^{\mathrm{Abc}}$ \\
\hline
\end{tabular}

Médias seguidas das mesmas letras maiúsculas nas colunas e minúsculas nas linhas não diferem significativamente entre si pelo teste de Tukey a $5 \%$ de probabilidade. 
Tabela 3. Valores médios de Matéria Seca (MS), Sólidos Solúveis Totais (SST), Acidez Titulável (AT), pH e Razão SST/AT do suco de maracujáamarelo, ao longo do período de amadurecimento dos frutos em duas épocas de colheita (EP 1 - maio/setembro e EP 2 - outubro/dezembro).

\begin{tabular}{|c|c|c|c|c|c|c|c|c|}
\hline \multicolumn{9}{|c|}{ Estádios de maturação (\% de cor amarela) } \\
\hline Medida & Colheita & 0 & 4,67 & 21,26 & 28,53 & 65,95 & 82,43 & 100 \\
\hline \multirow[t]{2}{*}{ MS (\%) } & EP 1 & $19,94^{\mathrm{Ab}}$ & $20,81^{\mathrm{Aab}}$ & $19,76^{\mathrm{Ab}}$ & $19,33^{\mathrm{Ab}}$ & $22,11^{\mathrm{Aa}}$ & $22,34^{\mathrm{Aa}}$ & $19,55^{\mathrm{Bb}}$ \\
\hline & EP 2 & $16,32^{\mathrm{Bdc}}$ & $15,58^{\mathrm{Bd}}$ & $16,00^{\mathrm{Bdc}}$ & $17,16^{\mathrm{Bc}}$ & $20,87^{\mathrm{Bab}}$ & $19,83^{\mathrm{Bb}}$ & $21,61^{\mathrm{Aa}}$ \\
\hline SST & EP 1 & $13,43^{\mathrm{Ab}}$ & $13,93^{\mathrm{Ab}}$ & $13,82^{\mathrm{Ab}}$ & $14,09^{\mathrm{Ab}}$ & $16,06^{\mathrm{Aa}}$ & $16,83^{\mathrm{Aa}}$ & $16,27^{\mathrm{Aa}}$ \\
\hline$\left({ }^{\circ}\right.$ Brix $)$ & EP 2 & $8,19^{\mathrm{Bb}}$ & $8,34^{\mathrm{Bb}}$ & $9,80^{\mathrm{Bb}}$ & $9,29^{\mathrm{Bb}}$ & $16,01^{\mathrm{Aa}}$ & $16,23^{\mathrm{Aa}}$ & $16,18^{\mathrm{Aa}}$ \\
\hline $\mathrm{AT}(\%)$ & EP 1 & $5,21^{\text {Aab }}$ & $5,32^{\mathrm{Aa}}$ & $5,37^{\mathrm{Aa}}$ & $5,16^{\text {Aab }}$ & $4,97^{\text {Aab }}$ & $4,93^{\mathrm{Aab}}$ & $4,64^{\mathrm{Ab}}$ \\
\hline (ácido cítrico) & EP 2 & $4,57^{\mathrm{Bab}}$ & $4,54^{\mathrm{Bab}}$ & $4,92^{\mathrm{Ba}}$ & $4,67^{\mathrm{Bab}}$ & $4,81^{\mathrm{Aab}}$ & $4,58^{\mathrm{Aab}}$ & $4,09^{\mathrm{Bb}}$ \\
\hline \multirow[t]{2}{*}{$\mathrm{pH}$} & EP 1 & $2,58^{\mathrm{Bbc}}$ & $2,59^{\mathrm{Bbc}}$ & $2,57^{\mathrm{Ac}}$ & $2,63^{\mathrm{Bb}}$ & $2,63^{\mathrm{Ab}}$ & $2,57^{\mathrm{Aabc}}$ & $2,70^{\mathrm{Aa}}$ \\
\hline & EP 2 & $2,71^{\mathrm{Aab}}$ & $2,71^{\mathrm{Aab}}$ & $2,61^{\mathrm{Ab}}$ & $2,72^{\text {Aab }}$ & $2,61^{\mathrm{Ab}}$ & $2,63^{\mathrm{Aab}}$ & $2,75^{\mathrm{Aa}}$ \\
\hline \multirow[t]{2}{*}{ SST/AT } & EP 1 & $2,66^{\mathrm{Ab}}$ & $2,42^{\mathrm{Ab}}$ & $2,58^{\mathrm{Ab}}$ & $2,72^{\mathrm{Ab}}$ & $3,26^{\mathrm{Aa}}$ & $3,33^{\mathrm{Aa}}$ & $3,53^{\mathrm{Ba}}$ \\
\hline & EP 2 & $1,79^{\mathrm{Bc}}$ & $1,85^{\mathrm{Bc}}$ & $2,01^{\mathrm{Bc}}$ & $2,01^{\mathrm{Bc}}$ & $3,35^{\mathrm{Ab}}$ & $3,58^{\mathrm{Aab}}$ & $4,02^{\mathrm{Aa}}$ \\
\hline
\end{tabular}

Médias seguidas das mesmas letras maiúsculas nas colunas e minúsculas nas linhas não diferem significativamente entre si pelo teste de Tukey a 5\% de probabilidade.

Posteriormente não ocorreram variações significativas até o final do amadurecimento. Silva et al. (2005) notaram incrementos progressivos de SST no maracujá até o estádio de maturação com 65\% de cor amarela. Pocasangre Enamorado et al. (1995) observaram que os frutos colhidos com mais de 50\% de coloração amarela diminuíram o conteúdo de SST e sugeriram que isto pode ter ocorrido devido à utilização de açúcares como fonte de carbono para a respiração e senescência dos frutos.

Marchi et al. (2000) observaram um incremento significativo de SST nos frutos colhidos entre os estádios com um terço e dois terços de coloração amarela, somente nas safras de menor temperatura e precipitação de chuvas, notando apenas um incremento não significativo nas safras de maior temperatura e precipitação de chuvas. O conteúdo de SST manteve-se constante nos frutos com mais de dois terços de cor amarela.

As diferenças nos teores de SST encontrados nos diferentes trabalhos com maracujá-amarelo podem ser conseqüências da variabilidade inerente à forma flavicarpa, entre frutos de diferentes plantas de um mesmo pomar (GAMARRA; ROJAS; MEDINA, 1994). Destaca-se, contudo, que a padronização dos frutos em cada estádio de maturação, utilizando as medidas de cor, contribui para a minimização da variabilidade das medidas de composição química e possibilita uma análise mais precisa da influência da época de colheita e do estádio de maturação sobre a qualidade do suco.

\subsection{Matéria seca (MS)}

Em relação ao conteúdo de MS do suco de maracujá-amarelo, os resultados mostraram que na EP 1 ocorreram maiores teores de MS do que na EP 2, até o estádio de maturação dos frutos com $82,43 \%$ de cor amarela, apresentando menor concentração de MS no estádio totalmente maduro (Tabela 3). Os maiores valores do conteúdo de MS nos estádios iniciais de maturação dos frutos da EP 1 podem ocorrer devido aos maiores teores de SST, quando comparados com a EP 2.

Destaca-se na Tabela 3 que o conteúdo de MS apresentou aumento significativo entre os estádios de maturação dos frutos com 28,53 e 65,95\% de cor amarela. Nota-se que este incremento na MS pode ser associado ao acúmulo de SST neste período.
A atividade metabólica mais intensa nos frutos colhidos na EP 2, que apresentaram maior incremento de SST durante o amadurecimento, pode justificar o maior conteúdo de MS no estádio maduro.

\subsection{Acidez titulável (AT)}

Nos estádios iniciais de maturação os frutos colhidos na EP 1 apresentaram uma acidez titulável média 12,3\% superior à daqueles colhidos na EP 2 (Tabela 3). Uma tendência de maior acidez na EP 1 foi observada nos estádios com 65,96 e 82,43\% de cor amarela, sendo que nos frutos maduros esta diferença atingiu a magnitude de $11,8 \%$, sendo maior que na EP 2. Estes resultados são coerentes com aqueles encontrados por Veras et al. (2000), que notaram que os frutos colhidos no período de abril a julho apresentam o suco ligeiramente mais ácido do que no período de outubro a dezembro. Ritzinger et al. (1989) verificaram a ocorrência de menor acidez em frutos colhidos no mês de fevereiro, quando as temperaturas foram mais altas e de maior precipitação e radiação solar do que no mês de maio.

Nas duas épocas de colheita ocorreu uma tendência de incremento de acidez no suco dos frutos com até $21,26 \%$ de cor amarela, atingindo magnitudes de 5,37\% na EP 1 e $4,92 \%$ na EP 2 (Tabela 3). Posteriormente, observou-se um declínio nas medidas de acidez até o final do amadurecimento, quando os frutos encontravam-se totalmente amarelados. De acordo com Ulrich (1970), os teores de ácidos orgânicos diminuem com a maturação dos frutos e, por serem importantes fontes de energia respiratória, estes ácidos são convertidos ou oxidados em açúcares e utilizados nas células.

Resultados semelhantes foram encontrados por Gamarra, Rojas e Medina (1996), que verificaram a existência de um acúmulo de ácidos orgânicos seguido por uma diminuição dos mesmos, quando se iniciaram os sinais de maturação. Entretanto, Pocasangre Enamorado et al. (1995) verificaram um acúmulo de acidez no início do amadurecimento do fruto, porém não observaram declínio no teor de acidez com o decorrer do amadurecimento.

Altos teores de ácidos no suco revelam uma característica importante para o processamento, sendo de interesse que os 
frutos possuam elevada acidez, visto que ela facilitaria sua conservação. O suco do maracujá-amarelo apresenta uma acidez elevada com relação ao suco de outros frutos tecnologicamente importantes, sendo superior em 34\% à do maracujá roxo, $75 \%$ à de goiaba, $90 \%$ à de manga e de abacaxi, mas 55\% inferior à de tamarindo (Nascimento, 1996).

\section{$3.6 \mathrm{pH}$}

Com respeito às medidas de $\mathrm{pH}$, os frutos colhidos na $\mathrm{EP} 1$ apresentaram menores valores do que os frutos colhidos na EP 2, nos primeiros estádios de maturação (Tabela 3). Nos estádios finais de maturação não se observaram diferenças entre as duas épocas de colheita, entretanto, ocorreram tendências de valores mais baixos de $\mathrm{pH}$ na EP 1 .

De maneira inversamente proporcional à acidez, nas duas épocas de colheita foi observada uma tendência de minimização dos valores de $\mathrm{pH}$ do suco até o estádio de maturação dos frutos com $21 \%$ de cor amarela, ocorrendo posteriormente um aumento dos valores até o estádio final de maturação. Marchi et al. (2000) também identificaram um aumento de pH do suco de frutos colhidos com mais de um terço de coloração amarela da casca.

\subsection{Razão SST/AT}

A razão SST/AT na EP 1 foi aproximadamente 33\% superior do que na EP 2, nos frutos colhidos com até 28,53\% de cor amarela da casca, devido ao maior conteúdo de SST. Nos estádios de maturação com 65,95 e 82,43\% de cor amarela, os valores foram estatisticamente iguais entre épocas, mas evidencia-se uma tendência de maior razão SST/AT na EP 2, sendo que nos frutos maduros as medidas são maiores na EP 2 (Tabela 3). Isto ocorreu porque a acidez titulável foi menor na EP 2 e o conteúdo de SST foi semelhante entre as duas épocas nos estádios finais de maturação dos frutos.

Pocasangre Enamorado et al. (1995) observaram um aumento da razão SST/AT durante toda a fase de desenvolvimento do fruto, atingindo o máximo no estádio de maturação em que os frutos se encontravam com $75 \%$ de coloração amarela. Silva et al. (2005) verificaram um incremento da razão SST/AT em frutos com até $65 \%$ de cor amarela.

Segundo Gamarra Rojas e Medina (1994), a razão SST/AT pode variar de acordo com a cultivar, o local e a época da colheita, mas durante o amadurecimento ela tende a aumentar, principalmente devido à diminuição da acidez.

De acordo com Nascimento (1996), a razão SST/AT é considerada uma das formas mais práticas de se avaliar o sabor dos frutos, sendo a acidez decisiva nesse quesito, pois se for alta, provoca a diminuição de seu valor. Saenz et al. (1998) estudaram a influência da data de colheita sobre as características do suco de maracujá roxo, notando que no inverno ocorreu uma razão SST/AT de 3,5 e no verão a razão foi da ordem de 6,6. Na avaliação sensorial verificaram que o suco de frutos de verão apresentou um aroma mais intenso e de melhor qualidade do que o suco de frutos colhidos no inverno. Ritzinger et al. (1989), avaliando o efeito de épocas em maracujás-amarelos colhidos em Viamão, RS, também verificaram uma diminuição da razão SST/AT em época de colheita com menor precipitação e radiação solar e de mais baixas temperaturas.

\section{Conclusões}

A evolução da cor amarela da casca do maracujá foi idêntica entre as duas épocas de colheita, porém o tempo de amadurecimento após a antese foi maior na época de colheita EP 1.

A composição química do suco foi influenciada pela época de colheita. Os frutos colhidos na época EP 1, com temperaturas mais amenas e de menor precipitação, apresentaram um suco com maiores conteúdos de acidez, matéria seca, sólidos solúveis totais e razão SST/AT do que os frutos da EP 2, para frutos com até $65 \%$ de cor amarela. A partir deste estádio de maturação, não ocorreu diferença significativa no conteúdo de SST entre as duas épocas. Entretanto, o suco dos frutos totalmente maduros apresentou menores conteúdos de matéria seca e da razão SST/AT na EP 1, além de uma acidez mais elevada.

Os maracujás-amarelos colhidos com mais de $65 \%$ de cor amarela da casca, na época de colheita EP 1, não alteraram a composição química do suco e, portanto, podem ser consumidos antecipadamente. No caso dos frutos da época de colheita EP 2, verificou-se a manutenção do conteúdo de SST, mas ocorreu incremento da razão SST/AT nos frutos maduros, sendo o padrão sensorial do suco provavelmente prejudicado em consumo antecipado.

\section{Agradecimentos}

Ao professor-orientador Romeu Vianni in memoriam. À FAPERJ e ao CNPq pelo apoio financeiro ao projeto e à CAPES pela bolsa de estudo.

\section{Referências bibliográficas}

ARAÚJO, R. C. et al. Produção e qualidade de frutos do maracujazeiro amarelo em resposta à nutrição potássica. In: XVI CONGRESSO BRASILEIRO DE FRUTICULTURA, 16, 2000, Fortaleza, CE. Anais... Caucaia: SBF, 2000. (CD-Rom).

AWAD, M. Fisiologia pós-colheita de frutos. São Paulo: Nobel, 1993. 140 p.

BERTHIER, L. J. et al. Estudo de filmes flexíveis na conservação do maracujá-amarelo. In: XVI CONGRESSO BRASILEIRO DE FRUTICULTURA, 16, 2000, Fortaleza, CE. Anais... Caucaia: SBF, 2000. (CD-Rom).

CARVALHO, A. J. C. et al. Adubação Nitrogenada e Irrigação no Maracujazeiro-amarelo. I-Produtividade e Qualidade dos Frutos. Pesquisa Agropecuária Brasileira, v. 35, n. 6, p. 1101-1108, 2000.

CRUZ, C. D. Programa GENES - versão windows (2004.2.1). Viçosa, MG: Editora UFV, 2001. 642p.

DURIGAN, J. F. Colheita e Conservação Pós-colheita. In: RUGGIERO, C. MARACUJÁ DO PLANTIO À COLHEITA. SIMPÓSIO BRASILEIRO SOBRE A CULTURA DO MARACUJAZEIRO, 5, 1998, Jaboticabal. Anais... Jaboticabal: Funep, 1998. p. 257-278.

GAMARRA ROJAS, G.; MEDINA, V. M. Maturação do fruto do maracujazeiro amarelo (Passiflora edulis Sims. f. flavicarpa Deg.). In: CONGRESSO BRASILEIRO DE FRUTICULTURA, 13, 1994, 
Salvador, BA. Caderno de Resumos...Cruz das Almas, BA: SBF, 1994. p. 833-834.

GAMARRA ROJAS, G.; MEDINA, V. M. Mudanças Bioquímicas do Suco do Maracujá Amarelo em Função da Idade do Fruto. Revista Brasileira de Fruticultura, v. 18, n. 1, p. 75-83, 1996.

HAFLE, M. O. et al. Características do maracujá-amarelo (Passiflora edulis Sims $f$. flavicarpa Deg.) comercializado no Município de Sousa, PB. In: Fábio Gelape Faleiro et al. Planaltina, DF: Embrapa Cerrados, 2005. 230p.

IBRAF. Instituto Brasileiro de Frutas. Disponível em: http://<www. ibraf.org.br/estatistica/producao >. Acesso em: 28 de ago. 2007.

MARCHI, R. et al. Uso da cor da casca como indicador de qualidade do maracujá amarelo (Passiflora edulis Sims. f. flavicarpa Deg.) destinado à industrialização. Ciência e Tecnologia de Alimentos, v. 20, n. 3, p. 381-387, 2000.

NASCIMENTO, T. B. Qualidade do maracujá amarelo produzido em diferentes épocas no sul de Minas Gerais. Lavras, MG, 1996. 56p. Dissertação - (Mestrado em Ciência de Alimentos), Universidade Estadual de Lavras.

POCASANGRE ENAMORADO, H. E. P. et al. Development and ripening of yellow passion fruit. Journal of Horticultural Science, v. 70, n. 4, p. 573-576, 1995.

RUGGIERO, C. et al. Maracujá para exportação: aspectos técnicos da produção. Brasília: EMBRAPA-SPI, 1996. 64p. (Série Publicações Técnicas FRUPEX, 19).

RITZINGER, R.; MANICA, I.; RIBOLDI, J. Efeito do espaçamento e da época de colheita sobre a qualidade do maracujá amarelo. Pesquisa Agropecuária Brasileira, v. 24, n. 2, p. 241-245, 1989.
ROSSI, A. D.; ROSSI, F. S.; SILVA, J. R. Análise Setorial. Produção de Sucos Tropicais: Maracujá. Vera Cruz: AFRUVEC, 2001. 47 p.

SAENZ, C. et al. Influence of harvest season on the characteristics of purple passion fruit (Passiflora edulis Sims.) and its juice. Food Science and Technology International, v. 4, n. 1, p. 45-51, 1998.

SALOMÃO, L. C. C. Colheita. Maracujá. Pós-colheita. Brasília: Embrapa Informação Tecnológica, 2002. 51 p. Frutas do Brasil, 23.

SEPÚLVEDA, E. et al. Color parameters of passion fruit juice (Passiflora edulis Sims): influence of harvest season. Food Science and Technology International, v. 2, n. 1, p. 29-33, 1996.

SILVA, T. V. (2004). Efeito da época de colheita e do estádio de maturação sobre as características físicas e químicas do maracujá amarelo (Passiflora edulis f. flavicarpa Degener). Campos dos Goytacazes, RJ, 2004. 84p. Dissertação - (Mestrado em Produção Vegetal), Universidade Estadual do Norte Fluminense Darcy Ribeiro.

SILVA, T. V. et al. Influência dos estádios de maturação na qualidade do suco do maracujá-amarelo. Revista Brasileira de Fruticultura, v. 27, n. 3, p. 472-475, 2005.

SOUZA, J. S. et al. Mercado Mundial. Maracujá. Pós-colheita. Brasília: Embrapa Informação Tecnológica, 2002. 51p. Frutas do Brasil, 23.

ULRICH, R. Organics Acids. In: HULME, A. C. The biochemistry of fruits and their products. New York: Academic Press, 1970. v. 1, p. 89-118.

VERAS, M. C. M.; PINTO, A. C. Q.; MENESES, J. B. Influência da época de produção e dos estádios de maturação nos maracujás doce e ácido nas condições de cerrado. Pesquisa Agropecuária Brasileira, v. 35, n. 5, p. 959-966, 2000. 